\section{Archaeological chemistry for the curious}

\section{Robert Hedges}

Archaeological Chemistry. By Z. Goffer. Pp. 376. (Wiley-Interscience: 1980.) £15.20, \$33.

THIS book should appeal most to those wishing for a quick canter around the field of applications of chemistry to archaeology. The first 75 pages give a crash course in chemistry - atoms and molecules in one page, analytical techniques in about 30 - so that, having learnt to sit in the saddle and keep his eyes open, the reader is briskly shown all the major 'sights' of archaeological chemistry.

With research in this area flourishing at present, the scenery is rich indeed. Topics range from ancient cement-making to amino-acid racemization dating; from metal corrosion and its conservation to the identification of dyes used in antiquity. As might be expected, most space is reserved for accounts of ceramics and of metallurgy, but room is also found for such less-common subjects as palaeotemperature measurement, soil surveys and authentication. Faced with all this, inexperienced readers will be grateful that the treatment of each topic is, perhaps inevitably, superficial. However, they will obtain a clear idea of the extent to which scientific definition can be imposed on the material with which the archaeologist deals, and a notion of some of the surprising results that can follow from the careful use of analytical techniques. References to original literature are frequently cited, although to benefit from them would demand a deeper knowledge than is provided by this book. The style is relaxed, but never unscientific, and the few mathematical hurdles that have not been avoided are taken easily.

Nevertheless, I doubt that the reader will finish the book with any specific knowledge of the kind of research being conducted now, either in terms of individual work or as more synoptic problems (for example, the geographical exploitation of tin during the Bronze Age, the invention of glazing technologies or the dissemination of iron smelting techniques). Nor would I expect an archaeologist reading this book to be much better able to evaluate critically the results of his colleagues' work. For example, in an area where such cooperation is particularly active - the determination of pottery provenance from the comparison of trace element distributions - the subject is treated in just four pages, has no mention of the statistical problems and only a hint of geochemical difficulties.
The subtitle, A Sourcebook..., makes claims that are not lived up to. Important books and journals are omitted in the bibliography, and comparatively few references are given beyond 1975 . To cover such a field with authority would require a much more penetrating book. However, no other single volume attempts

\section{Will we use the ocean wisely?}

\section{Henry Charnock}

Opportunities and Uses of the Ocean. By D. A. Ross. Pp. 320. (Springer-Verlag: 1980.) DM39.50, $\$ 21.80$.

ONCE upon a time and a very good time it was oceanography was the profession of a small number of (almost all) men. They devoted their energy, skill and persistence, and sometimes their money, to exploring, measuring and seeking to understand the complicated structure and motion of the sea. Not, one supposes, in the hope of immediate financial gain; apart from pioneers like Maury and Fitzroy, who realized that an understanding of winds to cover such wide ground, and this one can be recommended to those whose interest is based on curiosity rather than knowledge.

Robert Hedges is at the Research Laboratory for Archaeology, University of Oxford.

to the dumping of waste.

Not all of the proposed uses of the ocean are compatible and divergent views are strongly held by a range of interested groups. Dr Ross has set himself the question: "Where is the truth - what are the real problems and opportunities associated with the ocean?" He has attempted "to present some basic information about the ocean in a form that will be understandable to people who are not oceanographers, but who are interested and concerned about the marine environment". So the problems he is concerned with are not so much about the science as about the politics and legalities, while the opportunities are not to understand how the system works but how it can be exploited in a sensible (sustainable?) way.

An objective assessment needs the basic

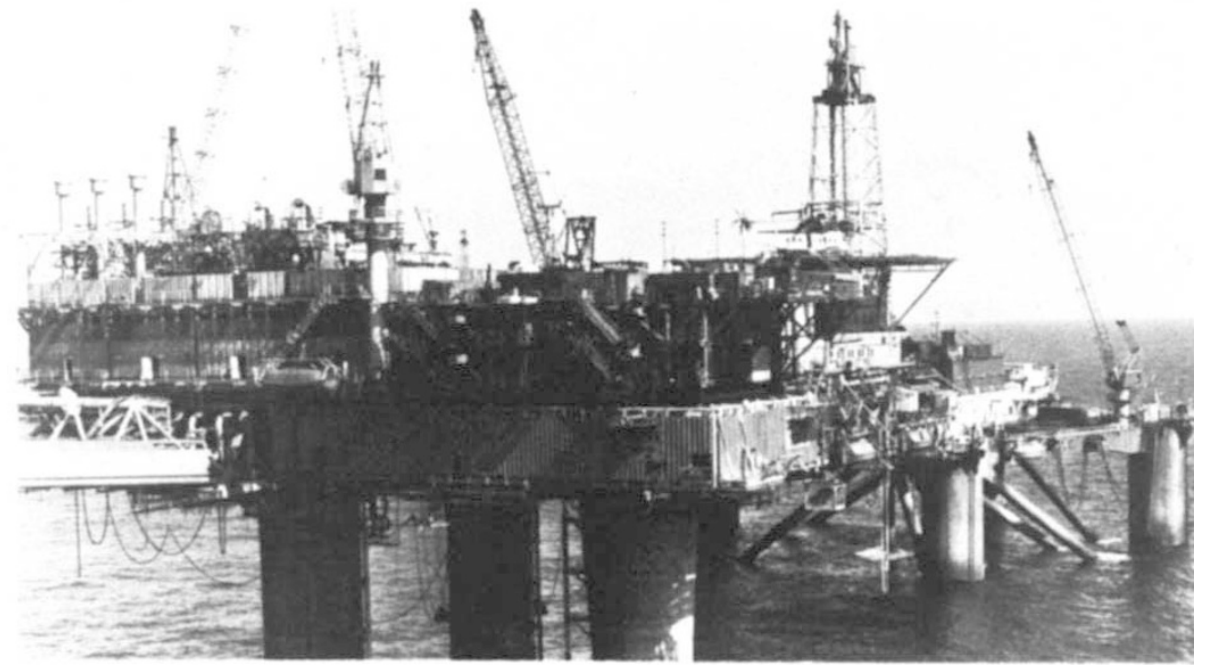

Energy from under the sea - a natural-gas rig in the North Sea

and currents could shorten sailing-ship passages and improve their owners' profits, most of the early marine scientists seem to have had only the most general notion that knowledge of the sea would prove useful.

Much more effort has been devoted to marine science since the Second World War, and even more money has been poured in since the great powers decided to deploy their nuclear weapons in submarines instead of aircraft. A vast amount of money is now spent in studying the ocean but with changed and more explicit motives - science is increasingly linked with technology and oceanic exploration has given way to exploitation, to the winning of food, minerals and energy and facts, so he gives $\mathbf{3 0}$ pages or so on "how the ocean works". It is difficult to compress such a broad subject into so little space - three pages to physical oceanography, for example - so it is not surprising that some of the explanation seems fluent rather than exact.

With finance as the only criterion, the most important users of the ocean are the navies of the world. Figures are hard to come by but it seems clear that a vast sum is spent each year on a range of activity and equipment mainly concerned with the detection of submarines. Anti-submarine warfare is a multi-billion dollar industry.

So the opacity of the ocean to electromagnetic radiation, which makes it dark, cold and mysterious, has led to a 